\title{
Slip-rolling resistance of high performance thin films and high toughness steel substrates under extreme conditions
}

\author{
C. Scholz, C.-A. Manier \& M. Woydt \\ BAM Federal Institute for Materials Research and Testing, Germany
}

\begin{abstract}
Nowadays, diamond-like carbon (DLC) coatings are mainly used in many low loaded applications such as in machine tools, computer devices and many more. Especially the automotive industry anticipates a benefit in applying such coatings in association with the lightweight construction of mechanical parts, for instance in gear components. The ulterior motive is a global performance increase regarding environmental impact and power efficiency. In recent years, the slip-rolling resistance of DLC, a-C and ta-C thin film coatings was improved considerably. In view of the mechanical application of thin film coatings, there is still room for improvements. It was experimentally shown, that a-C and ta-C coatings can be slip-rolling resistant at room temperature in unaddivated paraffin oil up to ten million cycles under Hertzian contact pressures up to $\mathrm{P}_{0 \max }=2.9 \mathrm{GPa}$. Typically, the prime coated steel substrates were made of the hardened and tempered steels $100 \mathrm{Cr} 6 \mathrm{H}$ and Cronidur 30. The aim of the work this to overtake these results, i.e. at higher maximum Hertzian pressures up to $\mathrm{P}_{0 \max }=4.2 \mathrm{GPa}$. Under such extreme conditions, it is necessary to choose special steels to avoid the failure of the substrate and to permit a higher load carrying capacity of the coating-substrate-system. In consideration of the increased substrate properties, two high toughness spring steels and an ultra-high toughness aerospace steel were tested on a twin disc tribometer of the Amsler type as well as on an Optimol TwinDisc test rig under mixed/boundary conditions. Different factors such as residual stresses of the substrate, influences of the lubrication, and wear behaviour were investigated. The respective results are presented here.
\end{abstract}

Keywords: slip-rolling, high toughness steel, DLC, a-C, thin film coating. 


\section{Introduction}

Original equipment manufacturers (OEMs) spur to meet the $\mathrm{CO}_{2}$-targets. Among others, three of the major directions of development axes are:

I. reduction in friction,

II. light-weight design and

III. increase in lifetime.

The whole powertrain offers at least as much room for functional improvements, as the internal combustion engine. The contributions of the powertrain to light-weight design are characterised by

a. reduced component sizes and

b. higher torques using iso-dimensions.

Both aspects increase the Hertzian contact stresses, the P x V-values (factors) and power density as well as the stresses in the materials core (volume). These highly demanding requirements for implementing light-weight strategies in powertrains, directly raise questions about the most promising technical solutions. It is clear, that any kind of solution must show an equal frictional profile, preferably a reduced friction, compared to the state-of-the-art and in the same time at least an equal lifetime. For tribosystems, the following paths may offer lower friction and higher load carrying capabilities:

I. thin film coatings (e.g. DLC),

II. alternative base oils and additives (such as esters, polyglycols) and/or

III. novel steels.

Although thin film coatings have pushed the tribological barriers to new heights, they still do not comply with the quality demands in mass production and functional needs in highly sophisticated tribosystems.

For using coatings on carbon steel substrates, two major issues have to be considered. Firstly, especially carbon containing coatings need to match the constitutional behaviour of the carbon steels. Secondly, the annealing temperature of these steels is generally not high enough to sustain the higher deposition temperature required for improved adhesion of the coating.

Novel, but already existing steel grades can withstand a sufficiently high deposition temperature for a necessary adhesion of modern coatings. In addition, these uncoated steel alloys also offer coefficient of friction as low as these shown by DLC and other types of coatings under mixed and boundary lubrication.

Chemicals, thus lubricants are subjected to many regulations in view of their environmental impact. In consequence, the number of available high 
performance additives will be restricted. Alternative base oils (esters, polyglycols) meet bio-no-tox criteria and offer an attractive tribological profile.

Although it is not imperative to respect these regulations be adhered to in all regions, keeping that in mind early in the product development cycle is both a corporate responsibility and good business practice. This is in line nowadays with the vision of business solutions based on the philosophy referred to as "Zeronize" [1, 2]. Zeronize symbolizes the efforts for the minimization of negative and adverse effects of energy conversion and/or mobility environment.

\section{Experimental conditions}

\subsection{The substrates}

In former investigations $[4,5]$ the substrates are mainly made of the quenched and tempered steels 100Cr6H (OVAKO 'PBQ') and Cronidur 30. Their hardness is in the range of $63-64 \mathrm{HRC}$ (Rockwell hardness $\mathrm{C}$ ) for the $100 \mathrm{Cr} 6 \mathrm{H}$ steel and 58 - 59 in the case of the Cronidur 30 . These steels are typically used in bearings.

In order to realize the light-weight design, especially in gear components in automotive applications, it is essential to utilise steel grades with high toughness and fatigue strength properties. Fig. 1 illustrates the increasing demands on material grades used for gear wheels. Hence, it is a major task to find a material solution which forms a good compromise between hardness in the tooth contact and ductility and basic strength of the tooth base. In consideration of the
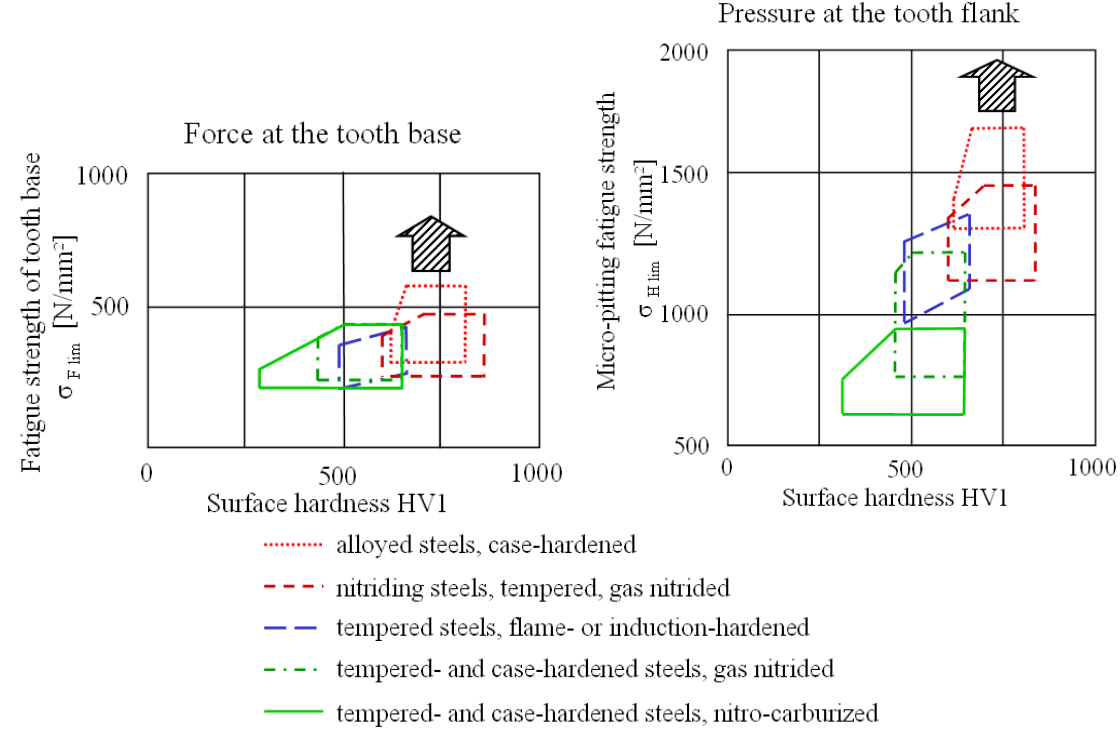

Figure 1: New demands on light-weight gear components derived from DIN 3990-5 (1987). 
increased demands placed on the substrate properties, two high toughness steels and an ultra-high toughness aerospace steel were selected for the new test series.

In case of the Ultra-High Toughness (UHT) steel grade, this material combines properties such as high surface hardness $(63-64$ HRC), hot hardness for usage up to $427^{\circ} \mathrm{C}$ and high fracture toughness. Previous investigations in rolling contact fatigue tests revealed a superior bearing life [7]. The special heat treatment of this steel starts with a VIM-VAR (Vacuum Induction MeltingVacuum Arc Remelting) melting, followed by a carburizing procedure, a double annealing $\left(10 \mathrm{~h}\right.$ at $\left.560^{\circ} \mathrm{C}\right)$ and finally a subzero cooling $\left(-196^{\circ} \mathrm{C}\right)$. This procedure generates the typical bearing requirement. The importance of special remelting processes for example on $100 \mathrm{Cr} 6 \mathrm{H}$ is presented in [9]. In order to transform a higher rate of austenite into a martensitic structure, the subzero cooling is necessary. This is the reason why not only the UHT steel was cooled at subzero temperatures but also the Cronidur 30, 100Cr6H and High Toughness I (HT I) steel.

Especially high deposition temperatures (during PVD/CVD-processes), i.e. in the range of annealing temperatures, can degrade the intrinsic tooth root load capacity of the steel, engendering of carbon steels a global weakening of the performances due to an ineffective material combination "gear material coating" [10]. A deposition temperature up to $>300^{\circ} \mathrm{C}$ makes the utilisation of stable steel grades in future applications essential.

A selection of the mechanical properties is shown in tab. 1. Steel grades with higher manganese sulphide $(\mathrm{MnS})$ contents are well-known for their protective effect especially in tool applications [8, 11]. Therefore, the steel grade 'High Toughness I' (HT I), with a low content of $\mathrm{MnS}$ and other inclusions, was selected for the tribological tests.

Table 1: $\quad$ Mechanical properties of steel substrates used.

\begin{tabular}{|l|c|c|c|c|c|}
\hline \multicolumn{1}{|c|}{ Substrate } & $\begin{array}{c}\text { 100Cr6H } \\
\text { (AISI 52100) }\end{array}$ & $\begin{array}{c}\text { Cronidur 30 } \\
\text { (AMS 5898) }\end{array}$ & $\begin{array}{c}\text { High } \\
\text { Toughness I }\end{array}$ & $\begin{array}{c}\text { High } \\
\text { Toughness II }\end{array}$ & $\begin{array}{c}\text { Ultra-High } \\
\text { Toughness }\end{array}$ \\
\hline $\begin{array}{l}\text { Density } \\
\rho\left[\mathrm{g} / \mathrm{cm}^{3}\right]\end{array}$ & 7.8 & 7.67 & 7.8 & 7.66 & 7.93 \\
\hline $\begin{array}{l}\text { Young's } \\
\text { modulus E } \\
{[\mathrm{GPa}]}\end{array}$ & 210 & 213 & n.d.a. & 202 & 211 \\
\hline Strain [\%] & n.d.a. & $<5$ & $\sim 10$ & $\sim 9$ & $<18$ \\
\hline Hardness [HRC] & 65.8 & 62.2 & 56.8 & 51.1 & 62.5 \\
\hline $\begin{array}{l}\text { Tenacity } \\
\mathrm{K}_{\mathrm{IC}}\left[\mathrm{MPa} \cdot \mathrm{m}^{1 / 2}\right]\end{array}$ & $\sim 16.5$ & $\sim 21$ & n.d.a. & $\sim 52$ & $>110$ \\
\hline $\begin{array}{l}\text { Bending strength } \\
\sigma_{4 \mathrm{~B}}[\mathrm{MPa}]\end{array}$ & $\begin{array}{c}>2000 \\
\text { (traction) }\end{array}$ & $\sim 1100$ & n.d.a. & n.d.a. & n.d.a. \\
\hline $\begin{array}{l}\text { Tensile strength } \\
\mathrm{R}_{\mathrm{m}}[\mathrm{MPa}]\end{array}$ & $\begin{array}{c}2300 \\
\text { (at } 61 \mathrm{HRC})\end{array}$ & $\sim 2300$ & $\sim 1600$ & $\sim 2150$ & $\sim 1840$ \\
\hline $\begin{array}{l}\text { Residual } \\
\text { austenite content } \\
{[\%]}\end{array}$ & 6.8 & 22.5 & $\begin{array}{c}\text { n.m. } \\
(<2.2 \%)\end{array}$ & 5.2 & 3.7 \\
\hline
\end{tabular}

n.d.a. - no data available, n.m. - not measurable (detection limit 2.2\%) 


\subsection{Test parameters}

The slip-rolling tribological tests were carried out in an Amsler-type twin disc tribometer and in a newly constructed Optimol TwinDisc tribometer. Fig. 2 presents a sketch of the arrangement of the discs in the Amsler-type. In general tests on twin disc tribometer are a good experimental method for technical applications, because they are a good compromise for simulating the real gear or bearing contact. The corresponding experimental parameters are shown in tab. 2 . In this testing machine, two discs with the same diameter roll against each other on their cylindrical surface.
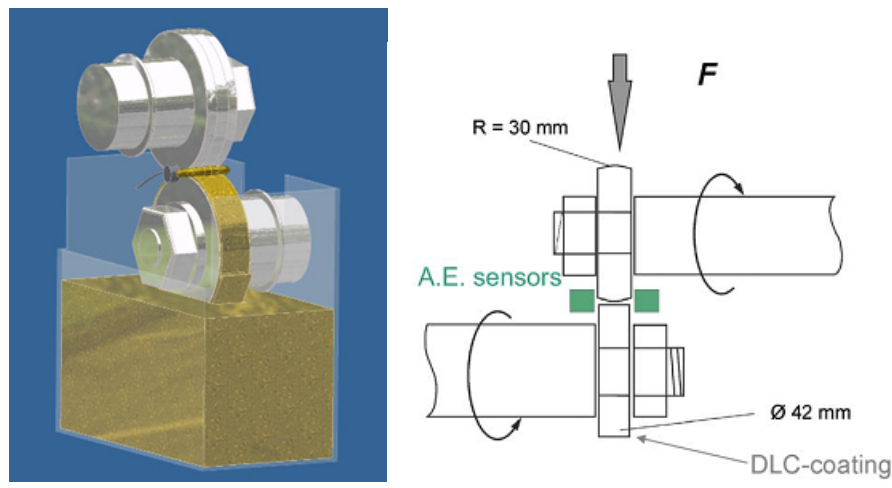

Figure 2: $\quad$ Specimen alignment and geometry in the Amsler- tribometer. The lower disc dips into a heatable oil reservoir during the tests.

Table 2: $\quad$ Experimental conditions.

\begin{tabular}{|l|l|}
\hline Conditions & Parameter \\
\hline Dimensions of the discs & Diameter: $42 \mathrm{~mm}$; Width: $10 \mathrm{~mm}$ \\
\hline Contact & $\begin{array}{l}\text { Grounded/ polished curved disc } \\
\text { (radius of curvature: } 30 \text { or } 21 \mathrm{~mm} \text { ) } \\
\text { against coated cylindrical disc }\end{array}$ \\
\hline Substrate & $\begin{array}{l}100 \mathrm{Cr} 6 \mathrm{H}, \text { Cronidur } 30, \mathrm{HT} \text { I, HT II, } \\
\text { UHT }\end{array}$ \\
\hline Type of motion & Rolling with a $10 \%$ slip rate \\
\hline Initial average Hertzian pressure $\mathrm{P}_{0 \text { mean }}$ & $1.5-1.94 \mathrm{GPa}\left(\mathrm{F}_{\mathrm{N}}=930-2000 \mathrm{~N}\right)$ \\
\hline Rotation at speed & $390-354 \mathrm{rpm}$ \\
\hline Sliding speed $\mathrm{V}_{\text {diff }}$ & $0.08 \mathrm{~m} / \mathrm{s}$ \\
\hline Cycles $\mathrm{n}_{\text {tot }}$ & $\begin{array}{l}\text { Up to } 10^{7} \text { or rupture (damaged } \\
\left.\text { surface area of } 1 \mathrm{~mm}{ }^{2}\right)\end{array}$ \\
\hline Sliding distance & Up to $13.2 \mathrm{~km}$ \\
\hline Surrounding temperature & $120^{\circ} \mathrm{C}$ oil temperature \\
\hline Lubrication & Factory fill oil SAE $0 \mathrm{~W}-30$ \\
\hline
\end{tabular}


The geometry of the discs with an outer diameter of $42 \mathrm{~mm}$ generates a contact of the ball-cylinder type. In the recent experiments the top, ball-shaped counter discs were uncoated and only pre-polished or 'as-grinded', turning at a speed of 354 revolutions per minute (rpm). The lower, cylindrical discs were coated and impelled at a rotating speed of $390 \mathrm{rpm}$, leading to a slippage of $10 \%$. The force is applied by means of a spring leading to an average Hertzian contact pressure from 1.0 up to $1.94 \mathrm{GPa}$. For comparison, an average contact pressure of $1.25 \mathrm{GPa}$ corresponds to a maximum Hertzian pressure of $\mathrm{P}_{0 \max }=1.875 \mathrm{GPa}$, which is equivalent to a load stage of 12 in the FZG test rig. This load stage is the most demanding test procedure for gears as described in the international standard ISO 14635-1. In order to gain practical advantages over additives containing, high performance lubricants, it is obvious that the coatings have to withstand Hertzian contact pressures much higher than FZG load stage of 12 (to avoid the useless development of a "stillborn technology").

The number of cycles, recorded by an optical sensor, was in the last years raised from 1 million up to10 million cycles in endurance tests. The vast metallurgical development and numerous practical experiences of recent years have forced to increase the number of cycles as well as to increase the contact pressure. For example, a test with 10 million cycles takes approximately 18 days. The number of cycles is one of the failure criterions in slip-rolling tests.

The development of the coefficient of friction (COF) and the wear volume cannot be as easily assessed as criterion for a critical damage. Previous test have shown that the rise in the COF is not necessarily followed by a failure of the coating. Therefore, damage was arbitrarily defined as 'critical', if a single damaged surface area of $1 \mathrm{~mm}^{2}$ could be observed. The size of such a flaked spot corresponds to 3 times the contact area at an initial, average Hertzian pressure of $1.0 \mathrm{GPa}$ (or equals the contact area at $1.5 \mathrm{GPa}$ ). It might occur that a certain coating is damaged in several locations leading to a total damaged area larger than $1 \mathrm{~mm}^{2}$. Such a coating would still count as 'resistant to slip-rolling', as long as none of the single damages exceeds an area of $1 \mathrm{~mm}^{2}$. This failure criterion has so far proven to be easy to handle, quick and successful. In recent literature, however, the total removal of the coating is proposed as failure criterion for lubricated slip-rolling tests [3]. This failure criterion ignores the fact that the coated part is no longer protected. The functionality of the system/component can no longer be guaranteed.

In the newly designed twin disc test rig, it is possible to test thin film coatings under mixed/boundary conditions up to an average Hertzian contact pressure of $\mathrm{P}_{\text {0mean }}=2.8 \mathrm{GPa}\left(\mathrm{F}_{\mathrm{N}}=5000 \mathrm{~N}\right)$. The aim of the development is to test the behaviour of thin films under extreme conditions. This test rig is powered by two electric motors, which actuates autonomous from each other. Thus, the slippage of the two discs is freely adjustable. In order to ensure comparableness of the results obtained on both test rigs the experimental conditions (rpm, slippage, lubrication, temperature) are always kept identical, except for the Hertzian contact pressure.

During the tests, the Castrol SAE 0W-30 factory fill oil (VP1) was used for lubrication. This oil was selected for its temperature resistance which permits to 
conduct long run tests at high temperatures $\left(120^{\circ} \mathrm{C}\right)$, typical for car engines. Applying the parameterized standard test conditions, each set of samples starts in the mixed and boundary regime. The regime of lubrication is important for the slip-rolling resistance. According to ref. [6] an evaluation of the minimal oil film thickness of the factory fill oil at $120^{\circ} \mathrm{C}$ at a load between 0 and $5000 \mathrm{~N}$ lead to a value of $h_{\min }=0.037-0.024 \mu \mathrm{m}$.

\section{Results of the slip-rolling resistance experiments}

First of all, reference tests were necessary to investigate the benefit of applying a coating on the cylindrical disc. Therefore, the samples were all tested under the aforementioned conditions without any coating and self-mated (uncoated steel vs. uncoated steel). Starting with a Hertzian contact pressure $\mathrm{P}_{0 \text { mean }}=1.5 \mathrm{GPa}$ further tests were carried out up to $1.94 \mathrm{GPa}$. Following the tests pictures in fig. 3 were taken of the wear track, stressed under $\mathrm{P}_{0 \text { mean }}=1.5 \mathrm{GPa}$, via optical microscopy. These pictures and the associated surface roughness (before testing) are presented in fig. 3 . The spherical counterbody is relatively undamaged, wear can be only found within the track. The cylindrical Cronidur 30 and $100 \mathrm{Cr} 6 \mathrm{H}$ discs used so far commonly show microcracks of about 20 to $100 \mu \mathrm{m}$ usually directed transversally to the rolling track and traces. In comparison to Cronidur 30 and $100 \mathrm{Cr} 6 \mathrm{H}$, the high toughness steel samples do not show microcracks or micro-pitting on such scale. Only SEM images at higher magnification show several initiating micro-pitting (cf. fig. 4).

Furthermore, the stylus profilometry is applied to quantify wear rates perpendicular to the sliding direction. The volumetric wear coefficient $\left(\mathrm{k}_{\mathrm{V}}\right)$ as result of the test with cylindrical and spherical discs is shown in fig. 3. In recent investigations $[4,5,6]$ coatings of different suppliers were tested and the wear rate was quantified. The coatings were deposited on the super-polished Cronidur 30 and $100 \mathrm{Cr} 6 \mathrm{H}$ steels. Fig. 5 indicates that a coating-substrate system against an uncoated disc entails a decreasing of the wear rate. A particular point to consider is the failure of coating $\mathrm{G}(5)$ after 3.29 million cycles. Local delamination of coating $\mathrm{G}(5)$ during the tests led to achieving the abort criterion and an increased wear coefficient. A high potential reveals the HT I alloy. With wear rates close to coated systems it can be assumed that a coating on this system benefits the wear rate of the coated cylindrical sample, except coating $\mathrm{G}(5)$. The question of whether the application of an expensive and elaborate coating makes sense, will be more clearly in comparison to uncoated systems. Coated cylindrical samples after 10 million cycles indicate to an approximately 4 times less wear coefficient than the uncoated discs. The a-C:H coatings I $(4,10$, 11) have indeed a higher hardness and Young's moduls $(\mathrm{H}=\sim 24 \mathrm{GPa}$ and $\mathrm{E}=$ $200 \ldots 214 \mathrm{GPa})$ than the a-C coating $\mathrm{G}(5)(\mathrm{H}=19 \mathrm{GPa}$ and $\mathrm{E}=204 \mathrm{GPa})$. It can be assumed that the hardness and/or the Young's modulus of the coating have an important influence on the wear mechanism [6]. So the different properties of both coating types cause consequently to higher wear especially of the uncoated counterpart or in extreme case to failure of the coating. 


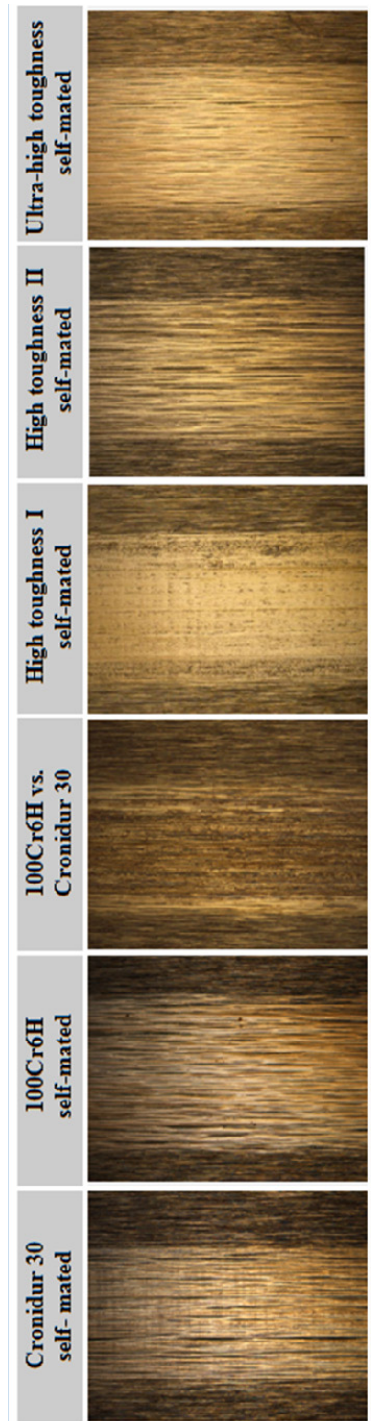

рәฺвоэип рив рәриฺ̣.
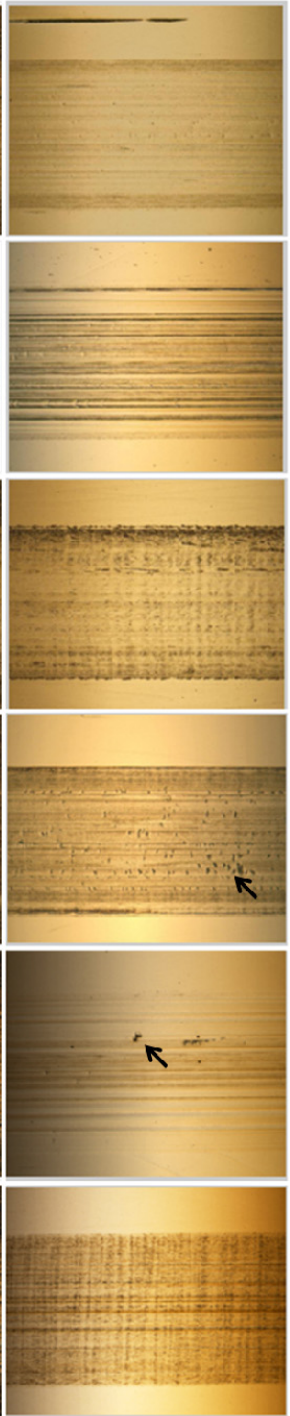

рәุвоэนก puв рәчs!! $0^{\circ} \mathrm{d}$
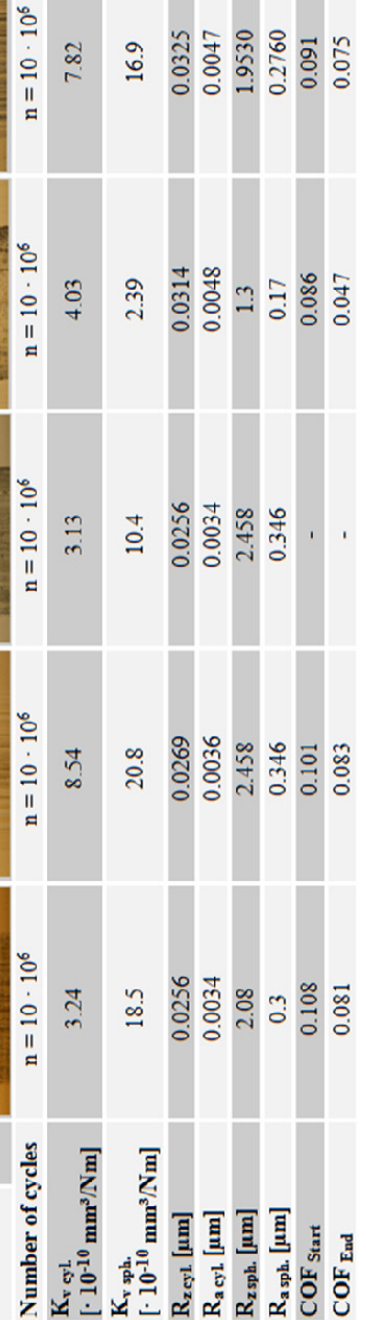

a

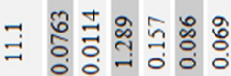

$\stackrel{+}{\circ}$

음

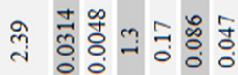

$\because$

t.

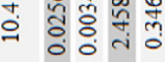

긍 ڤ

药

a
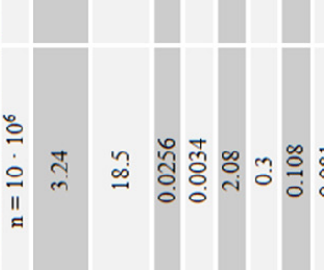

(5)

氖

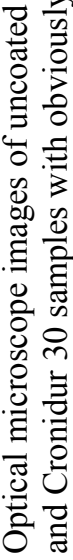

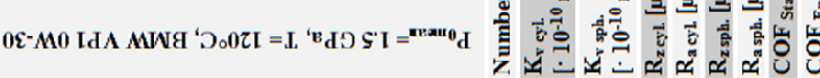

$\ddot{\sim}$ 

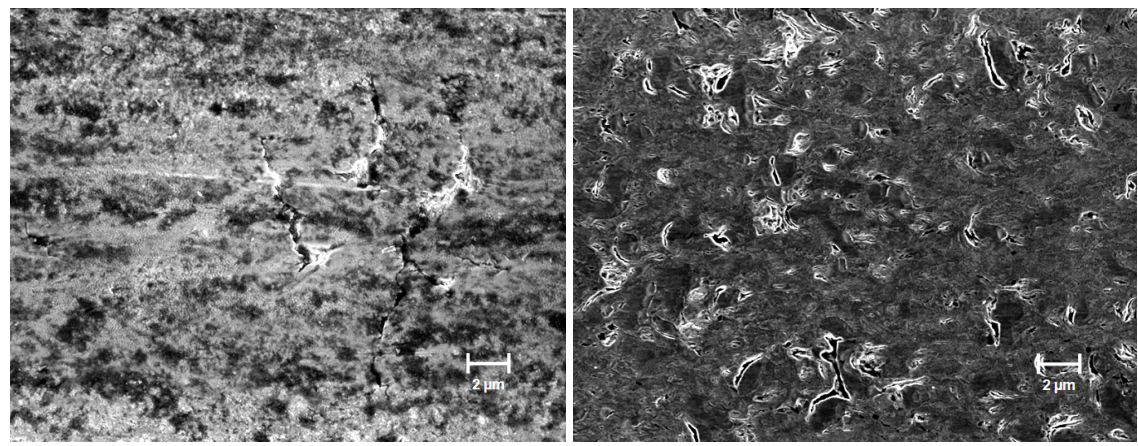

Figure 4: $\quad$ SEM images of HT II and UHT steel inside the wear track with a 10.000x magnification.

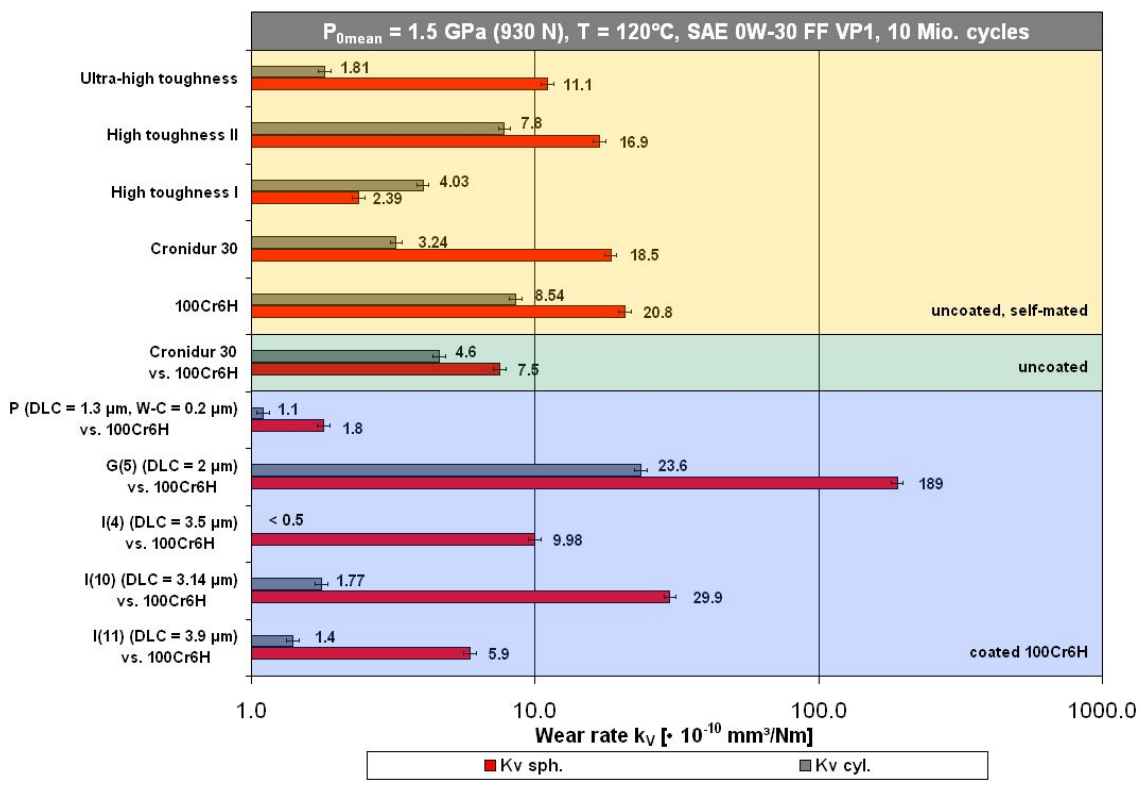

Figure 5: Comparison of wear rates $\mathrm{k}_{\mathrm{V}}$ of different steel-steel and steel coating combinations. Test of coating $\mathrm{G}(5)$ interrupted after 3.29 million cycles.

Looking at the COF at the beginning and end of the tests as one of tribological criterions, uncoated UHT and HT I are with $\mathrm{COF}_{\text {End }}$ of 0.047 and 0.069 in the range of steel-coating-systems [4]. Fig. 6 show distinct differences between the both solutions. Assuming that fact, it can be said, that a thin film coating enhances the reduction in friction (COF).

In order to show the benefit of the novel high toughness alloys it was necessary that the tests were carried out under more stringent conditions. For this 


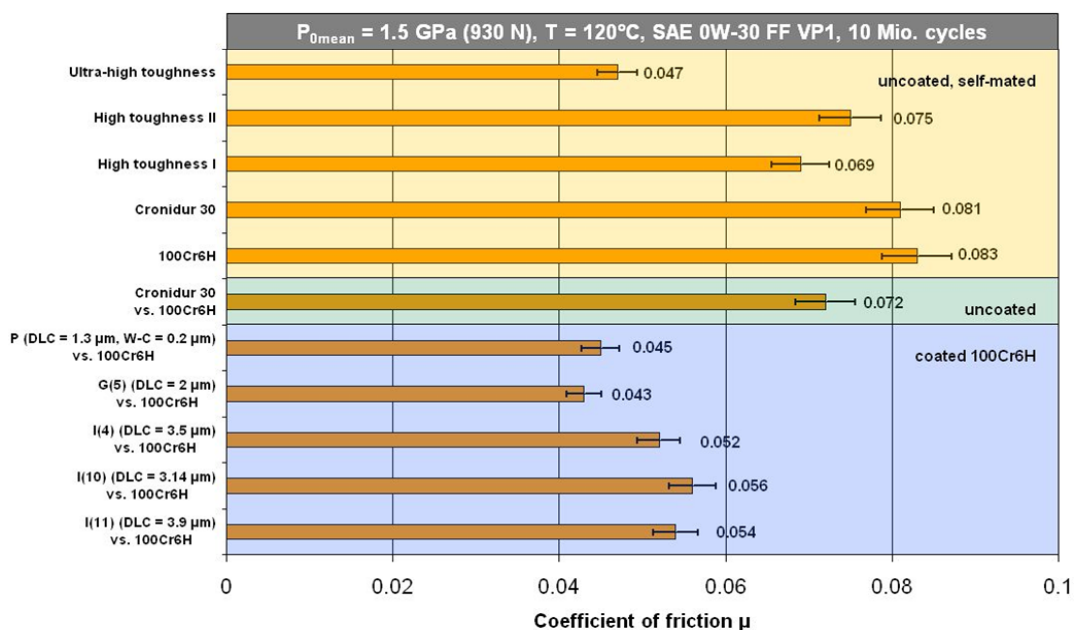

Figure 6: Comparison of the coefficient of friction at the end of the test $\mathrm{COF}_{\text {End }}$ of different steel-steel and steel-coating combinations.

reason the uncoated steel samples were tested at a higher Hertzian contact pressure of $\mathrm{P}_{0 \text { mean }}=1.94 \mathrm{GPa}$, conditions in which Cronidur 30 and $100 \mathrm{Cr} 6 \mathrm{H}$ exhibit macro-pitting and in some areas micro cracks on the $>50 \mu \mathrm{m}$ scale. SEM investigations of the UHT sample after 10 million cycles revealed small, marginal cracks $(\sim 2 \mu \mathrm{m})$ in chromium carbid enclosures (cf. fig. 7). The carbides were detected by means of EDX-element mapping. HT I and HT II showing similar surface conditions with singular microcracks on the scale of $4 \mu \mathrm{m}$. Pictures of optical microscopy and the test results can be found in fig.8.
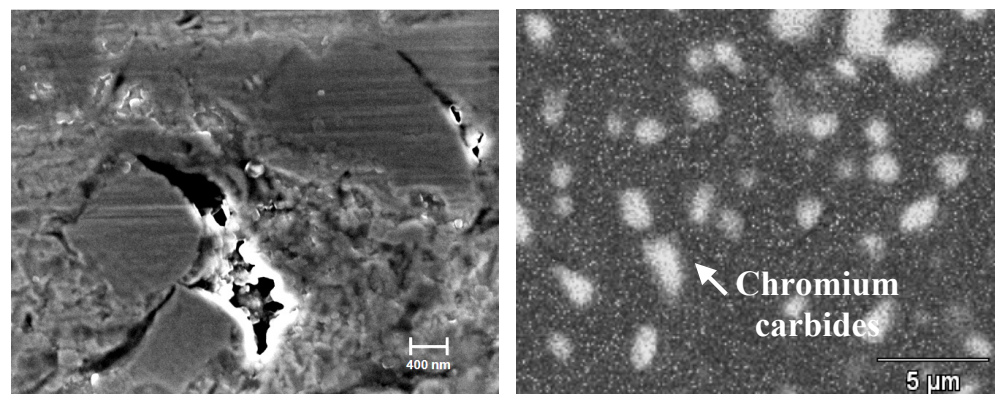

Figure 7: Chromium carbides of UHT inside the wear track with 50.000x (left) magnification and on the right EDX detected carbides $(20 \mathrm{kV}$, $15.000 x)$.

By using $\mathrm{P}_{0 \text { mean }}=1.94 \mathrm{GPa}$ the wear rates of the uncoated high toughness steels remained in the same order of magnitude, by the COF of HT I was with 0.059 closed to thin film coatings. 


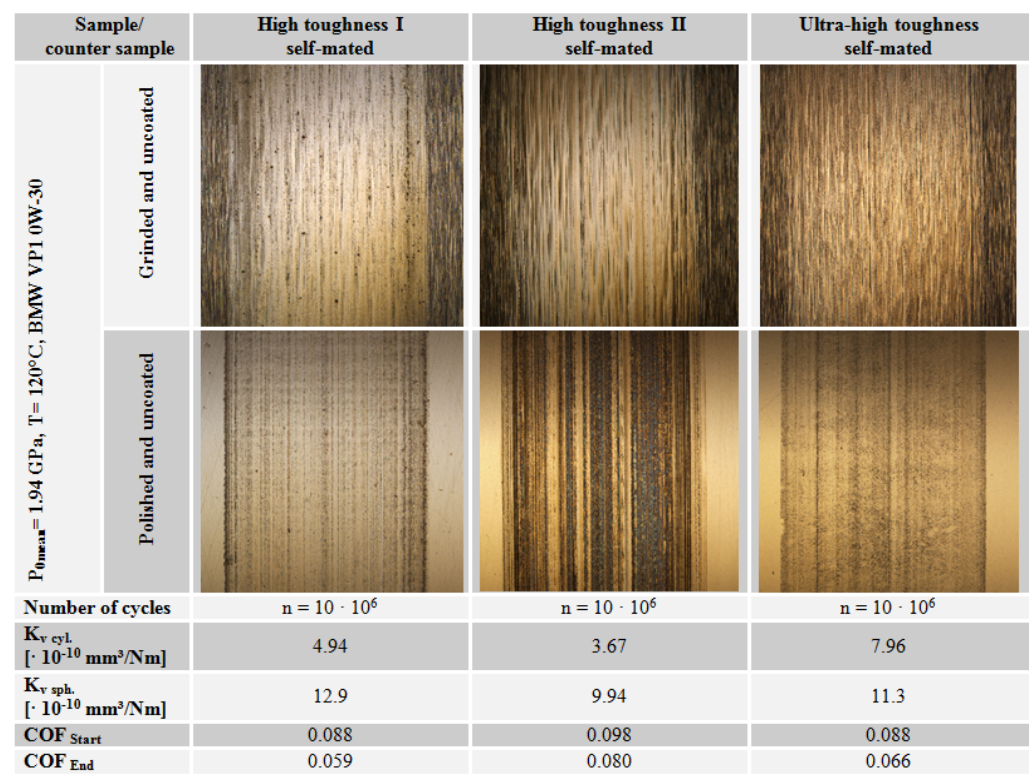

Figure 8: Optical microscope images of uncoated discs and their counter bodies after test at $\mathrm{P}_{0 \text { mean }}=1.94 \mathrm{GPa}$.

\section{Conclusion}

In this contribution, advantages in slip-rolling resistance of high toughness steel grades under Hertzian contact pressures up to $1.94 \mathrm{GPa}$ (mean pressure or in $\mathrm{P}_{0 \max }=2.94 \mathrm{GPa}$ ) were demonstrated. With the application of these uncoated alloys it is possible to withstand higher load carrying capabilities at temperatures of $120^{\circ} \mathrm{C}$ without failure of the substrate. This represents a necessity in order to push thin film coatings to higher contact pressure, as they offer low COFs. Even the wear rate of several uncoated steels lies in the range of steel-coating-systems. For comparison, the wear rates for the uncoated high toughness steels were on the cylindrical disc in the range of 1.8 to $7.8 \cdot 10^{-10} \mathrm{~mm}^{3} / \mathrm{Nm}$ under identical testing conditions. Distinct differences between uncoated and coated steel matches required concerning the $\mathrm{COF}$ at the end of the tests. The COFs of coated samples were in the range of 0.043 to 0.056 whereas the COF of uncoated samples was situated at a higher level of 0.069 to 0.083 . The only exception is the UHT steel with a COF of 0.047 . With a low wear rate and COF this alloy offers a high potential in following tests.

In future investigations it is planned to analyse, how a coating on the cylindrical disc will affect the wear behaviour and the COF of the uncoated steelsteel system up to a maximum Hertzian contact pressure of $\mathrm{P}_{0 \max }=4.2 \mathrm{GPa}$. It is essential to change the perception of DLC coatings being an 'expensive problemsolver' towards DLC's being a reliable and advanced solution for applications under extreme conditions. 


\section{References}

[1] Toyoda, S., All Toyota tribological innovation to realize "Zeronize" and "Maximize" society, Tribology Online, Vol. 2, No. 1, pp. 19 - 22, 2007 [Japanese Society of Tribologists, www.tribology.jp].

[2] Renault, S.A., Sustainable development - "ELLYPSE" - radically designed, Das Magazin für Forschung und Entwicklung, No. 26, October 2002, Publisher: Renault, S.A., Direction de la Communication, rue du Vieux-Pont-de-Sèvres, F-92109 Boulogne-Billancourt, ISSN: 1289-009x.

[3] Liu, S.J., Hua, D.Y., Wear Behaviour of W-DLC Coating under Reciprocating Sliding Motion, ASTM D02 Symposium on wear and friction test methods for coatings and surface treatments, Miami Beach, 21. June 2007.

[4] Manier, C.-A., Spaltmann, D., Woydt, M., Tribology of DLC films under slip-rolling conditions. Tribology of Diamond-like Carbon Films: Fundamentals and Applications, ed. C. Donnet and A. Erdemir, SpringerVerlag: Berlin, pp. 385 - 409, 2008.

[5] Manier, C.-A., Spaltmann, D., Theiler, G., Woydt, M., Carboneous coatings by rolling with $10 \%$ slip under mixed/boundary lubrication and high Hertzian contact pressures. Diamond and Related Materials, 17, pp. $1751-$ 1754, 2008.

[6] Woydt, M., Manier, C.-A., Brückner, A., Weihnacht, V., Slip-rolling resistant thin film ta-C coatings for up to $3.000 \mathrm{MPa}$ of Hertzian contact pressure, Proc. of the $50^{\text {th }}$ Tribology-Symposium, Gesellschaft für Tribology e.V.: Göttingen, 55/1, 21. - 23. September 2009.

[7] Tomasello, C.M., Burrier, H.I., Knepper, R.A., Balliett, S., Maloney, J.L., Progress in the evaluation of CSS-42L: A high performance bearing alloy, Bearing Steel Technology (STP 1419), ed. J.M. Beswick, ASTM International, pp. 375 - 398, 2002.

[8] Flacelière, L., Sourmail, T., d'Eramo, E., Daguier, P., Dabas, H., Marchand, J., Steel solutions designed for wind mills, Publisher: Ascometal, Immeuble le Colisée 8, avenue de l'Arche Faubourg de l'Arche, 92419 Courbevoie Cedex, France.

[9] Ölund, P., Material development for increased demands in windmill applications, Publisher: Ovako Group Headquarters, Box 5013, SE-194 05 Upplands Väsby, Sweden

[10] Bugiel, C., Tribologisches Verhalten und Tragfähigkeit PVD-beschichteter Getriebe-Zahnflanken, Apprimus Verlag, Aachen, pp. 108-115, 2009.

[11] Durand, J.M., Jeandin, M., Influence of manganese sulfide (MnS) addition on the wear behavior of M3/2 high-speed steel. Tribology Letters, 2, pp. $247-261,1996$. 